\title{
Long-length tubular Electrode-Tools from Composite Material for Electrical Discharge Machining of Hard Alloys
}

\author{
Evgeny Shalunov ${ }^{1}$, Valentin Smirnov ${ }^{1}$, Vladimir Plotnikov ${ }^{1}$, and Yulia Vladimirova ${ }^{1, *}$ \\ ${ }^{1}$ Chuvash State University, Joint R\&D Laboratories of Mechanically Alloyed Nano-Composite \\ Materials, their Technology and Quality, 428015 Cheboksary, Moscovsky Prospekt 15, Russia
}

\begin{abstract}
The article deals with long-length tubular electrode-tools made of the engineered composite [(WC+3wt $\% \mathrm{Co})+3 w t \% B N)]+14 w t \% \mathrm{Cu}$, which, during electrical discharge piercing of holes in a hard alloy WC+6wt\%Co (ISO 513:2012) in the optimal mode, have a productivity that is almost 8 times higher than the productivity of the process, when it is performed using copper electrode-tools. Therewith, electrical discharge wear of the electrode-tools made of the new material is $4.1 \ldots 4.5$ times less than the wear of the copper electrode-tools. To obtain hollow electrodetools from the specified material, the powder composition was radially molded by the pressure of a impulsed magnet field, and the resulting porous blank was impregnated with copper during its further sintering.
\end{abstract}

\section{Introduction}

One of the most popular and widespread operation of electrical discharge machining (EDM) of metallic materials is electrical discharge piercing of holes in difficult-to-machine materials (high-alloy and hardened steels, hard alloys) in the manufacture of punching and piercing dies, press dies, casting molds, various meshes, removal of a broken tool or fastener, etc. [1,2]. Most often, a solid electrode-tool is used to perform such operation (Fig. 1, a). In this case, all the material removed from the hole, as a rule, is irrecoverable losses, which are borne by the cost of the product made using EDM. Moreover, operating conditions of such an electrode-tool are extremely difficult, since only its outer surface is cooled by the working medium (for example, kerosene), and due to the poor heat removal, the electrode-tool quickly wears out, and the process of piercing is carried out with low level of productivity [1-3].

The need to ensure high productivity of the process, reduce wear of the electrode-tool and, as a result, reduce the cost of the blank, determines the relevance of the issues of creating the required electrode-tool for electrical discharge piercing of holes, especially of difficult-to-machine metallic materials.

Currently, there is a significant amount of electrode materials for electrical discharge machining [1-5], however, only those of which it will be possible to make a hollow electrode-tool can be promise (Fig. 1, b).

\footnotetext{
* Corresponding author: yulivladimirova@mail.ru
} 


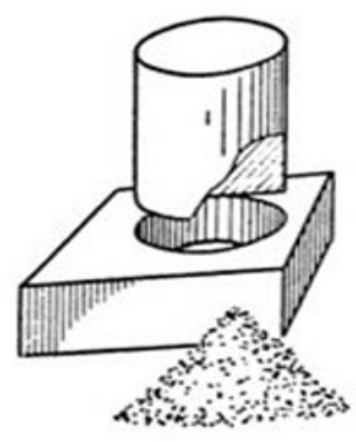

a

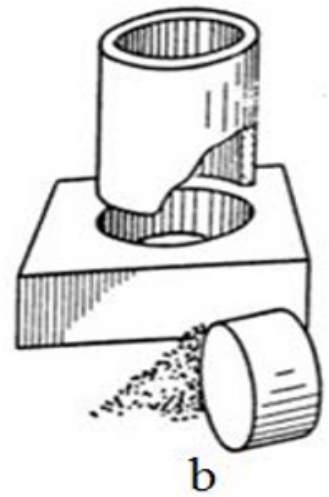

Fig. 1. Electrical discharge piercing of through hole by solid (a) and hollow (b) electrode-tool.

Presence of a through hole will significantly improve heat removal from the electrodetool, increase the productivity of machining in pieces and reduce the specific electrical discharge wear of the tool. For example, in the paper [2], it is shown that when making through holes in parts made of steel or heat-resistant alloys using a tubular electrode-tool, when its linear wear is compensated by its longer length, the processing can be carried out in forced modes at increased electric current densities, reaching $0.8 \mathrm{~A} / \mathrm{mm}^{2}$. In this case, the working fluid is pumped through the hole in the electrode-tool, thereby ensuring its good cooling. Wear ratio of the tubular electrode-tool in these modes is $40 \ldots 50 \%$ of the solid electrode-tool wear ratio.

Fig. 1,b shows that the thinner the wall of the electrode-tool, the larger the diameter of the cut cylindrical "waste», which may not be considered as such, since it can serve as a blank for any other part. It seems clear that reduction in the electrode-tool wall thickness can be realized only, where it is possible to make the correct choice of material and ensure the manufacture of a thin-walled electrode-tool with a considerable length.

As it is known $[1,3,4]$, materials for manufacture of the electrode-tool used in the EDM of difficult-to-machine metallic materials should have increased heat resistance, high melting temperature, electrical discharge resistance at sufficiently high values of thermal and electrical conductivity. These requirements are in relative conflict with each other. For example, copper could serve as a material that could meet the requirements for good thermal and electrical conductivity, but at the same time it should have a refractoriness, such as, for example, have tungsten, tungsten carbide or molybdenum. However, tungsten or hard alloys of tungsten carbide with copper do not form solutions of evident concentration either in liquid or solid states. However, in mixtures, they additively combine properties inherent in each of them separately. It is obvious that such «artificial» materials (pseudo - alloys) are very difficult to obtain using conventional metallurgical methods, and, as a rule, powder metallurgical practices are used.

For these purposes, the most interesting is the powder pseudo alloy of the WC+Co composition, additionally containing copper and an additive in the form of boron nitride $\mathrm{BN}$, designed to increase the electrical discharge resistance of the electrode-tool [6-8]. However, BN does not interact with the pseudo-alloy components, but it is located at the grain boundaries and on the surface of WC, $\mathrm{Co}$ and $\mathrm{Cu}$ particles, preventing their sintering and shrinkage, which causes a large porosity of the sintered electrodes. However, low ( 2 ... $3 \mathrm{wt} \%$ ) content of $\mathrm{BN}$ in the composition contributes to the formation of a finegrained structure of the pseudo alloy. High electrical discharge resistance of the electrodetool made of the above composition with small additions of BN is associated with the formation of a honeycomb structure, where copper is partially enclosed in the skeleton of 
$\mathrm{WC}+\mathrm{Co}$ and in refractory honeycombs of BN, where strong capillary forces arise that prevent evaporation of copper from the electrode-tool during operation.

Electrodes-tools of the above material are made, mainly, by pressing a powder mixture that does not contain copper powder, sintering the resulting blanks (which are a refractory porous frame) and further impregnation of the sintered blank (frame) with copper. This process makes it possible to obtain a solid electrode-tool; however, its length should not be more than $2 \ldots 2.5$ times greater than its diameter. In this case, the diameter cannot be more than $30 . . .40 \mathrm{~mm}$, as otherwise, the frame in the electrode central part will not be filled with copper during impregnation.

It seems clear that it is impossible to make a high-quality hollow electrode-tool of such a material using this method, especially a thin-walled one, because, when axially pressing a tubular finished product of large length, its density along the length will be nonuniform and, therefore, properties of the electrode material will be also anisotropic and will certainly affect its performance.

In view of the above, in this paper, an attempt was made to obtain such an electrode-tool by using the energy of a impulsed magnetic field during cold pressing, which provides a high-speed and dynamic process of powder materials compaction resulting in denser press forming [9].

\section{Experimental materials and methods}

Basic substances were powder of a hard «tungsten carbide - cobalt» pseudo - alloy WC+ 3 wt\% Co (ISO 513:2012) and a powder of hexagonal boron nitride, grade B (RUTechnical requirements 2112-003-49534204-2002). These powders in the ratio of $97 \mathrm{wt} \%$ of the $\mathrm{WC}+3 \mathrm{wt} \%$ Co pseudo-alloy powder to $3 \mathrm{wt} \%$ of the BN powder were intensively mixed for $60 \mathrm{~min}$ and partially crushed in an attritor with a working chamber capacity of 15 liters at a rotor speed of $600 \mathrm{~min}^{-1}$ [10]. Then the resulting powder composition was used to obtain tubular blanks, from which the electrode-tools for EDM were further made.

Tubular blanks made of a powder composition $(\mathrm{WC}+\mathrm{Co})+\mathrm{BN}$ were obtained by discharging a impulsed magnetic press MIU-20/5 (Table 1) onto an inductor (Fig. 2), in the hole of which a tooling with the indicated powder composition was installed.

Table 1. Performance specification of the impulsed magnetic press MIU-20/5.

\begin{tabular}{|c|c|c|}
\hline Specification & Unit & Value \\
\hline Stored energy & $\mathrm{kJ}$ & 20 \\
\hline Maximum charge voltage & $\mathrm{kV}$ & 5 \\
\hline Condenser bank capacity & $\mu \mathrm{F}$ & 1600 \\
\hline Short discharge resistor circuit frequency & $\mathrm{KHz}$ & 12.6 \\
\hline
\end{tabular}

To prepare this tooling (Fig. 3) for operation, the powder composition 8 was poured into the radial clearance between the electrically conductive shell 5 and the steel mandrel 1 coaxially installed in the shell. To prevent the powder mixture from spilling out, two steel plugs 4 and 6 were used, as well as a washer 6 , which was pressed against the shell 5 by a nut 7. The steel spacer sleeve 2 and the ring 3 served to remove the mandrel 1 from the tubular powder blank obtained as a result of crimping (pressing).

A multi-turn plate inductor with a work bore with a diameter of $22 \mathrm{~mm}$ was used as a tool for crimping the current-conductive shell (see Fig. 2). Each turn of the inductor consisted of two plates made of a bulk nanostructured material of the $\mathrm{Cu}-\mathrm{Al}-\mathrm{C}-\mathrm{O}$ system, grade C16.105 DISCOM ${ }^{\circledR}$ (RU-Technical requirements TU 1479-002-13092819-2001). This material with a relative electrical conductivity of 92\% IASC has a recrystallization temperature of $830^{\circ} \mathrm{C}$ and an ultimate tensile strength of $450 \mathrm{MPa}[11,12]$. 


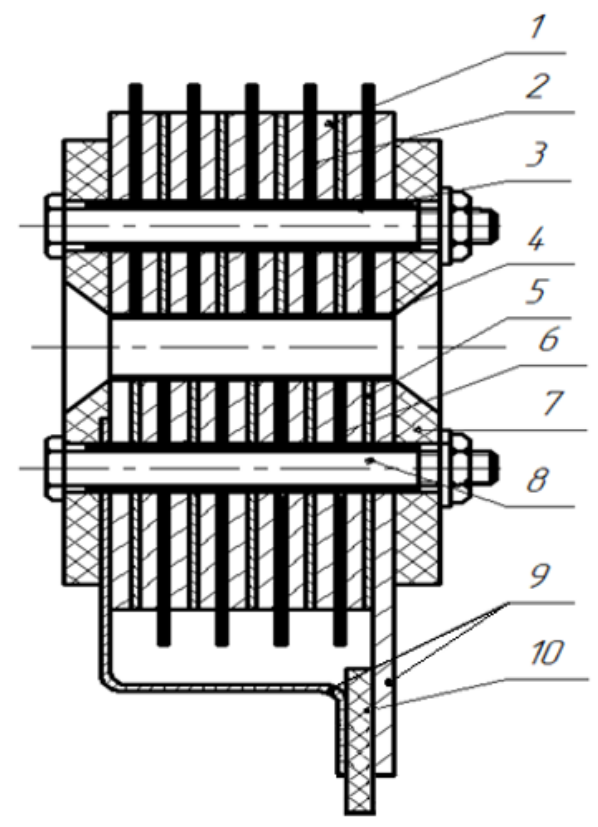

Fig. 2. Overview of the five-turn plate inductor for radial impulsed magnet pressing of powder composition: 1 - plate; 2 - plate-to-plate insulation; 3 - insulating bushing; 4 - basic insulation; 5 contact plate; 6 - turn-to-turn insulation; 7 - frame; 8 - bolt; 9 - current-carrying terminal; 10 insulating plate.

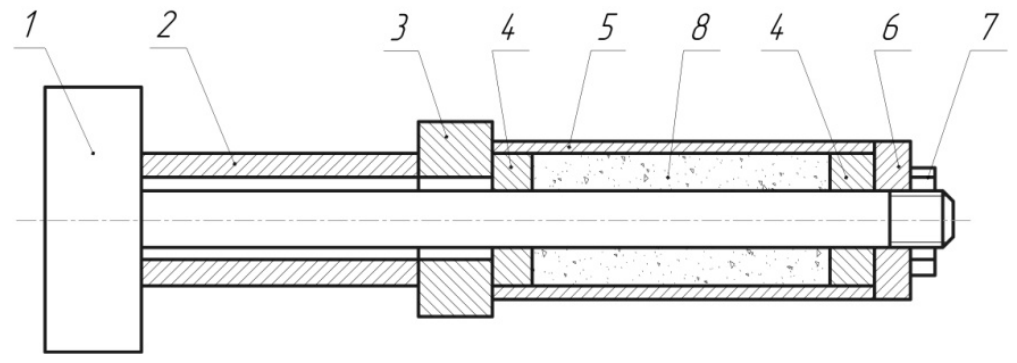

Fig. 3. Schematics of tooling for radial radial impulsed magnet pressing of a powder composition in an electrically conductive sheath.

To obtain compacts serve as blanks for further manufacture of electrode-tools, electrically conductive shells of annealed copper with an outer diameter of $20 \mathrm{~mm}$, a length of $70 \mathrm{~mm}$, and a wall thickness of $1.5 \mathrm{~mm}$ were used. The mandrels were made of steel 1.0503 with a diameter of its shaft of $8 \mathrm{~mm}$. To ensure removal of the mandrel from the pressed blank, the mandrel bearing length was grinded and, before filling with the powder composition, was lubricated with a boron nitride-glycerin mixture.

The samples were crimped at different impulse magnetic press energy values, and the mandrel then was removed from the pressing on the R-50 tensile testing machine by clamping mandrel 1 and ring 3 (with nut 7 removed) on the tensile grips. Removal of the copper shell from the pressing was carried out on a lathe machine by turning.

Then the relative density of tubular compacts was determined, and the dependence of their relative density on the energy expended by the impulsed magnetic press was plotted. The required relative compact density of $80 \%$ corresponds to an energy of $12.8 \mathrm{~kJ}$. 
Once this is done, the same experiments were carried out on radial pressing of the powder composition using a copper sheath with the magnetic-impulse unit energy of 12.8 kJ. However, after the tubular compact was pressed out, the copper sheath was not removed. A steel pipeline connected to a vacuum pump was tightly installed in the pressing hole, and this structure was placed in a tubular electric resistance furnace, which was first heated up to $980^{\circ} \mathrm{C}$, held at this temperature for 45 minutes, and then the temperature in the furnace rose to $1150 \ldots 1180^{\circ} \mathrm{C}$, and at this temperature, the copper shell was melted, and the copper was penetrated radially into the compact wall. Then the sample was quickly removed from the furnace and cooled in the open air. After cooling, the sample was turned along the outer diameter and faced.

The sample made of the hollow electrode-tool (Fig. 4) was cut along the length into rings $5 \mathrm{~mm}$ long, and the relative density of these rings was determined, after which the relative density curve was plotted along the length of the electrode-tool. The Rockwell hardness of the rings in the end plane was also determine.

Analysis of copper in the obtained samples was made using a russian emission spectrometer DFC-500.

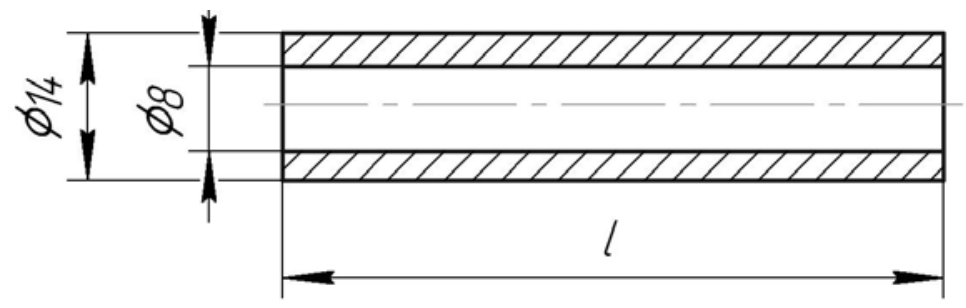

Fig. 4. Schematics of a sample of the electrode-tool obtained by radial impulse magnetic pressing of a powder composition $\mathrm{WC}+\mathrm{Co}+\mathrm{BN}$ and its impregnating with copper.

Testing of the manufactured hollow electrode-tools was carried out in comparison with hollow electrode-tools made of commercial copper M1 in the form of cold-drawn calibrated tubes. For this purpose, electrical discharge piercing of holes was carried out on a universal EDM piercing machine with a normal grade of accuracy, model 4G721M. Each electrode, in the same mode, pierced three holes in the plates of hard alloy WC+6 wt \% Co (ISO 513:2012) in a kerosene medium with a plane sizes of 25x30 mm and a thickness of $6 \mathrm{~mm}$. In these conditions, the time $t$ taken by the electrode for piercing each hole was recorded, which was averaged for all three holes. During the tests, parameters of the process mode current density $j$, current frequency $f$, and no-load voltage $U_{\mathrm{xx}}$ - were varied.

According to measurements of the electrodes-tools before and after piercing, its electrical discharge wear was assessed.

\section{Experimental results and their discussion}

Measurements and weighing of the manufactured blanks of the electrode-tools made it possible to conclude that the average relative density along the length of the electrode-tool was from $94 \%$ to $97 \%$ of the full density of its material. Therewith, density distribution along the length of the electrode-tool was uniform: the density difference along the length did not exceed $\pm 5 \%$ of the average density along the electrode-tool length. Concentration of copper in the electrode-tools manufactured blanks was $14 \pm 1 \mathrm{wt} \%$.

Table 2 shows the values of the time $t$ for the electrical discharge piercing of holes in the hard alloy WC+6wt\%Co (ISO 513:2012) plates using electrodes-tools made of different materials. 
Table 2. Time for EDM hole piercing using electrodes-tools made of different materials.

\begin{tabular}{|c|c|c|c|c|c|}
\hline \multirow{2}{*}{ Variant No. } & \multicolumn{2}{|c|}{ Processing mode parameters } & \multicolumn{3}{|c|}{ Average time for hole piercing $t$, min } \\
\cline { 2 - 6 } & $\begin{array}{c}J, \\
\mathrm{~A} / \mathrm{mm}^{2}\end{array}$ & $\begin{array}{c}f, \\
\mathrm{KHz}\end{array}$ & $\begin{array}{c}U_{\mathrm{xx}}, \\
\mathrm{V}\end{array}$ & Copper & {$[$ [(WC+3wt\%Co)+3wt\%BN)]+14wt\%Cu } \\
\hline 1 & & & & & 41 \\
\hline 2 & 0.45 & 8 & 90 & 347 & 26 \\
\hline 3 & 1.80 & 22 & 105 & 209 & 23 \\
\hline 4 & 1.20 & 44 & 120 & 257 & 33 \\
\hline 5 & 1.40 & 8 & 45 & 171 & 22 \\
\hline 6 & 1.40 & 22 & 50 & 144 & 18 \\
\hline 7 & 1.40 & 44 & 50 & 221 & 28 \\
\hline
\end{tabular}

Data analysis presented in Table 2 shows that the total time of piercing holes using electrodes-tools made of composite material $[(\mathrm{WC}+\mathrm{Co})+\mathrm{BN})]+\mathrm{Cu}$ for all 7 process modes is $88 \%$ less than the total time of piercing the same holes using electrodes-tools made of copper. Based on the data analysis given in the table, it can also be noted that the most optimal mode for electrical discharge piercing of holes in the above hard alloy WC+6wt\%Co (ISO 513:2012) is mode No. 6: $j=1.4 \mathrm{~A} / \mathrm{mm}^{2} ; f=22 \mathrm{KHz} ; U_{\mathrm{xx}}=50 \mathrm{~V}$. In this mode, the time for piercing holes using electrode tools made of both materials was minimal.

Knowing the amount of material occupied by the hole made in the plate $\left(923.2 \mathrm{~mm}^{3}\right)$ and the average time spent on piercing one hole, the process average productivity was calculated, which was $6.4 \mathrm{~mm}^{3} / \mathrm{min}$, when it was made using a copper electrode-tool, and $51.3 \mathrm{~mm}^{3} / \mathrm{min}$, when the hole was pierced using the electrode-tool made of composite material [(WC+3wt\%Co)+3wt\%BN)]+14wt\%Cu.

It follows that productivity of the electrical discharge piercing of $\mathrm{WC}+6 \mathrm{wt} \% \mathrm{Co}$ hard alloy using electrode-tools made of the engineered composite material in the optimal mode is almost 8 times higher than productivity of the process, when it is performed using copper electrode-tools.

It should also be noted that electrical discharge wear of the electrode-tools made of the new material was 4.1 ... 4.5 times less than the wear of the copper electrode-tools.

Wastes of hard alloy produced during piercing in the form of disks with a diameter of $7.5 \ldots 7.7 \mathrm{~mm}$ and a thickness of $6 \mathrm{~mm}$ can be used according to intended purpose of this hard alloy (inserts into stamping tools, cutting tools, wearing parts of machines, instruments and measuring tools, etc.).

\section{Summary}

As a result of the research conducted, long-length tubular electrode-tools were made of the engineered composite material $[(\mathrm{WC}+3 \mathrm{wt} \% \mathrm{Co})+3 \mathrm{wt} \% \mathrm{BN})]+14 \mathrm{wt} \% \mathrm{Cu}$, which during the electrical discharge piercing of holes in the WC+6wt\%Co (ISO 513:2012) hard alloy showed significantly higher process productivity compared to copper electrode-tools. At the same time, the electrode-tools made of the new material have significantly less electrical discharge wear compared to the wear of the copper electrode-tools. 


\section{References}

1. E.C. Jameson, Electrical Discharge Machining (Society of Manufacturing Engineers, Dearborn Michigan, 2001)

2. M. P. Jahan, Electrical discharge machining (EDM): types, technologies and applications (Nova Publishers, New York, 2015)

3. M.L. Levit, O.V. Padalko, Materials and methods for the manufacture of shaped electrodes-tools of electroerosive copying and sewing machines (Research Institute of Mechanical Engineering, Moscow, 1975)

4. N.D. Ogleznev, K.R. Muratov, T.R. Ablyaz, S.B. Preetkanwa, S.S. Sarabjeet, IOP Conf. Series: Materials Science and Engineering 510 (2019)

5. G. Sémon, A practical guide to electro-discharge machining, 2nd ed. (Ateliers des Charmilles S.A., Geneva, 1975)

6. N.D. Ogleznev, S.A. Oglezneva, O.V. Dolivets, K.A. Mazurenko, O.P. Morozov, Modern Problems of Science and Education 6 (2014)

7. T. Thankachan, K. S. Prakash, M. Loganathan, Materials and Manufacturing Processes 33, 3 (2017)

8. S. Chen, Yu. Bi, H. Zhang, J. of Composite Materials 49, 30 (2015)

9. A.I. Gusev, A.A. Rempel. Nanocrystalline Materials (GISP, Cambridge, 2004)

10. Y. O. Vladimirova, E. P. Shalunov, IOP Conf. Series: Materials Science and Engineering, 525, 1 (2019)

11. E. Shalunov, A. Matrosov, L. Chen, Proc. of Int. Congress \& Exhibition on Powder Metallurgy (Euro PM - 2008), v. 1, pp.113-119 (EPMA, Mannheim, 2008)

12. V. Dovydenkov, E. Shalunov, Proc.of Powder Metallurgy - 1998 World Congress, v. l, pp.372-376 (EPMA, Granada, 1998) 